\title{
Gene-Modified Tumor Cell Vaccine Therapy
}

National Cancer Institute

\section{Source}

National Cancer Institute. Gene-Modified Tumor Cell Vaccine Therapy. NCI Thesaurus.

Code C116539.

A type of immunotherapy in which tumor cells have been modified to make them more immunogenic, thereby activating the immune system to attack and destroy the tumor. 